\title{
Investigation of rotations in isomerism forms of a ylide of theophylline: Dynamic ${ }^{1} \mathrm{H}$ NMR study
}

\section{SAYYED MOSTAFA HABIBI-KHORASSANI ${ }^{1, *}$, MEHDI SHAHRAKI ${ }^{1}$, EIDEH MOFARRAH ${ }^{1}$ and ELHAM MOFARRAH ${ }^{2}$}

\begin{abstract}
${ }^{1}$ Department of Chemistry, University of Sistan and Baluchestan, P. O. Box 98135-674, Zahedan, Iran. ${ }^{2}$ Department of Chemical Engineering, Amirkabir University of Technology, Tehran, Iran.

*Corresponding author E-mail: smhabibi@chem.usb.ac.ir
\end{abstract}

http://dx.doi.org/10.13005/ojc/330316

(Received: January 23, 2017; Accepted: March 03, 2017)

\begin{abstract}
The internal rotations around the some within a ylide involving theophylline has been studied using the dynamic ${ }^{1} \mathrm{H}$ NMR spectroscopic technique in different temperatures. The kinetic and activation quantities were calculated. Arrhenius, Eyring and classic methods were applied for isomers. compared for carbon-carbon double, carbon-carbon single bond for $Z$ isomer. The results obtained by classic method was different with data calculated from Arrhenius and Eyring methods while these methods were consistent together.
\end{abstract}

Keywords: Ylide, Isomerism, Dynamic ${ }^{1} \mathrm{H}$ NMR, Activations Parameters

\section{INTRODUCTION}

Ylides are important compound in the synthesis of plenty products with the various applications in pharmacology and medicine ${ }^{1-7}$. Moreover, theophylline characterized s1, 3-dimethylxanthine, is known as an impressive bronchodilator drug ${ }^{8}$. This compound has been used for over half a century in the treatment of asthma and remains the most widely prescribed anti-asthma treatment in the whole world ${ }^{9}$. This compound also used in treatment chronic pulmonary obstructive disease (COPD) 0 10-11-12-13,
anti-Inflammatory ${ }^{9,14}$, immunomodulatory ${ }^{9}$, air ways smooth muscle effects ${ }^{15-16}$, effects infant sapnea ${ }^{17,18}$. Theophylline is naturally in green and black tea, coffee, and cocoa ${ }^{19}$.

Theophylline in structure of ylides has significant dynamic ${ }^{1} \mathrm{H}$ NMR effects. So, these effects afford important information regarding the rotational isomers ${ }^{2,20-25}$.

In this work, the dynamic ${ }^{1} \mathrm{H}$ NMR effects on the titled compound prepared of the reaction between triphenylphosphine 1 and 
dimethylacetylendicarboxylaten 2 in the presence of theophylline 3 has been described. The synthesis reaction has been previously reported ${ }^{26}$. For these reasons, three methods for determining the activation parameters are applied ${ }^{27}$.

\section{Chemicals and instruments}

Tiphenylphosphine1, dimethyl acetylene dicarboxylate 2 and theophylline 3 obtained from Fluka (Buchs, Switzerland) are used in analytical grade,. The extra pure solvents including ether and acetone- $d_{6}$ (supplied by Merk, Darmstadt Germany) are used in this work. The ${ }^{1} \mathrm{HNMR}$ spectra were recorded on a FTNMR 400.22 MHz-BRUKERAvance III.

\section{RESULTS AND DISCUSSION}

The presence of two isomers $\mathrm{Z}$ nd $\mathrm{E}$ for the synthesized ylide 4 was confirmed by the ${ }^{1} \mathrm{H},{ }^{13} \mathrm{C}$ and ${ }^{31} \mathrm{P}$ NMR spectra (Fig .1) ${ }^{26}$.

The adjacent carbonyl group along with the three rotations around the restricted rotational bonds of the synthesized compunds is strongly conjugated in the $Z-4$ and $E-4$ rotational isomers (Fig. 2).
${ }^{1} \mathrm{H}$ NMR spectra of the ylide4 showed two doublets for methine proton $(\mathrm{H}-\mathrm{C}-\mathrm{C}=\mathrm{P})$ and methyl groups $\delta=5.493-5.510$ and 3.69-3.72 ppm, for the minor and major geometrical isomers, respectively. All interchangeable process of rotational isomers for ylide 4 involving isomers I, II, III, IV, V and VI are shown in Fig. 3

Dynamic effects for the Z-4 and E-4 rotational isomers around the carbon-carbon double bond (Fig. 3, a, I and II)

The ${ }^{1} \mathrm{H}$ NMR spectrum for the $4-\mathrm{Z}$ and the 4-E (Fig. 3, a, I and II) at $-0 \mathrm{C}(273.15 \mathrm{~K})$ exhibited two sharp doublets for the methene proton $(\mathrm{H}-\mathrm{C}-\mathrm{C}=\mathrm{P}$, ${ }^{3} \mathrm{JPH}$ ) in acetone. This spectrum is broadened at $20^{\circ} \mathrm{C}(293.15 \mathrm{~K})$. The resonance coalescence occurred at near $26{ }^{\circ} \mathrm{C}(299.15 \mathrm{~K})$ that they belong to rotational process around carbon-carbon double bond. The methoxy proton resonance coalescence is accrued at near $32{ }^{\circ} \mathrm{C}(305.15 \mathrm{~K})$. The coalescence temperature $\left(T_{c}\right)$ and isotropic chemical shift $(\Delta v)$ is obtained for the maximum peak separation in the low-temperature limit ${ }^{27}$. Moreover, parameters and kinetic parameters are calculated by the classic method and tabulated ${ }^{1}$ in Table 1.<smiles>CC(=O)C#COC(C)=O</smiles>

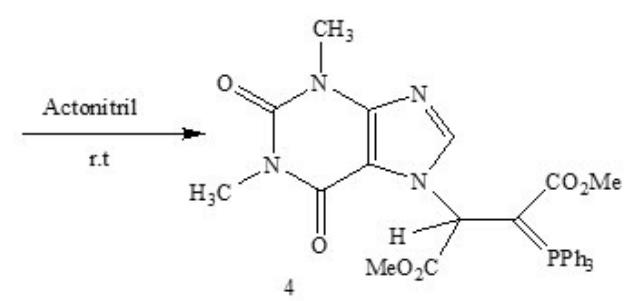

Fig. 1: Synthesise of dimethyl-2-(Theophylline-1-yl)-3-(triphenylphosphoranylidene) butandioate4 from the reaction between triphenylphosphine1 and dimethyl acetylene dicarboxylate 2 with theophylline 3
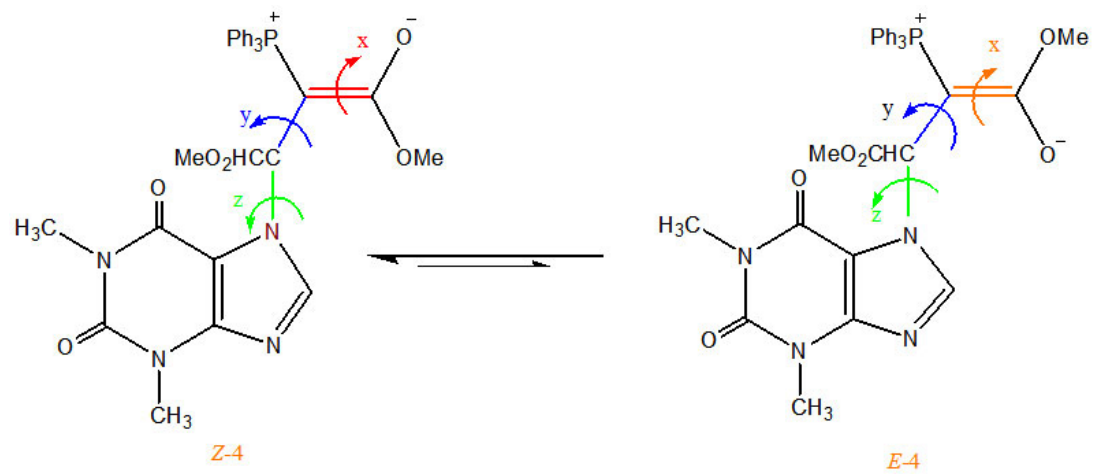

Fig. 2: Three possible rotations for the interchangeable processes of the two isomers ( $Z$ - and E-) in ylide4 
For completing analysis and reducing the errors, the determining of activation parameters are repeated by Eyring and Arrhenius methods. With using the average value of $\Delta G^{\ddagger}$ in various temperature (Table 2), $\ln (k / T)$ and Ink can be drawed according to the Eyring ${ }^{1}$ and Arrhenius $^{2}$ equations ${ }^{27}$. The Eyring and Arrhenius plots are shown in Figs. 4A and 5 , respectively. In addition, a different linearized from of Eyring equation has been employed to draw Fig. 4B for determination of $\Delta H^{\ddagger}$ (activation enthalpy) and $\Delta S^{\ddagger}$ (activation energy) ${ }^{28-30}$ :

$\operatorname{Tln}(\mathrm{k} / \mathrm{T})=\mathrm{T}\left(23.76+\Delta S^{\ddagger} / \mathrm{R}-\Delta H^{\ddagger} / \mathrm{RT}\right)$

By using some correlation reported previously by researchers, the standard errors

Table 1: The activation parameters forylide4 around the carbon-carbon double bound (Entry a,Fig. 3)

\begin{tabular}{|c|c|c|c|c|c|c|c|}
\hline $\begin{array}{l}T_{\mathrm{c}} \\
\mathrm{K}\end{array}$ & $\begin{array}{c}\delta \\
\text { ppm }\end{array}$ & $\begin{array}{l}\Delta v \\
\mathrm{~Hz}\end{array}$ & $\begin{array}{l}k_{c} \\
\mathbf{S}^{-1}\end{array}$ & $\begin{array}{c}\Delta \boldsymbol{G}^{\ddagger} \\
\text { kcalmol-1 }^{-1}\end{array}$ & $\begin{array}{c}\Delta \boldsymbol{H}^{\#} \\
\text { kcalmol }^{-1}\end{array}$ & $\begin{array}{c}\Delta \boldsymbol{S}^{\ddagger} \\
\text { calmol }^{-1} \mathbf{K}^{-1}\end{array}$ & $\begin{array}{c}E_{\mathrm{a}} \\
\text { kcalmol-1 }^{-1}\end{array}$ \\
\hline 299.15 & $\begin{array}{c}5.493- \\
5.510\end{array}$ & 6.8 & 15.10 & 15.90 & & & \\
\hline 305.15 & $\begin{array}{c}3.699- \\
3.729\end{array}$ & 12.01 & 26.66 & 15.88 & 16.58 & 2.28 & 17.17 \\
\hline
\end{tabular}

Table 2: Values of $\Delta G^{\ddagger}$, Ink/T and Ink for rotation around carbon-carbon double bond (Entry a, Fig. 3)

\begin{tabular}{cccccccc}
\hline$T_{c} \mathbf{K}$ & $\mathbf{1 / T}$ & $\Delta \delta \mathbf{p p m}$ & $\Delta v \mathbf{H z}$ & $\Delta \mathbf{G} \neq \mathbf{k c a l} / \mathbf{m o l}$ & Lnk/T & Lnk & TxLnk/T \\
\hline 263.15 & 0.00380 & $5.479-5.494$ & 6.00 & 14.05 & -4.41 & 1.16 & -1159.965 \\
273.15 & 0.00366 & $5.493-5.510$ & 6.80 & 14.51 & -3.38 & 2.23 & -922.154 \\
283.15 & 0.00353 & $5.508-5.529$ & 8.40 & 14.93 & -2.42 & 3.23 & -684.656 \\
293.15 & 0.00341 & $5.524-5.545$ & 8.40 & 15.45 & -1.52 & 4.15 & -477.053 \\
\hline
\end{tabular}

Table 3: A comparing between the results obtained by the three methods for the rotation around the carbon-carbondouble bond in the isomer Z-4 and E-4 [entry a]

\begin{tabular}{lllll}
\hline Methods & $\Delta \mathbf{G}^{\ddagger}\left(\mathbf{k c a l m o l}^{-1}\right)$ & $\Delta \mathbf{H}^{\ddagger}\left(\mathbf{k c a l m o l}^{-1}\right)$ & $\Delta \mathbf{S}^{\ddagger}\left(\right.$ calmol $\left.^{-1} \mathbf{K}^{-1}\right)$ & $\mathbf{E}_{\mathbf{a}}\left(\mathbf{k c a l m o l}^{-1}\right)$ \\
\hline Classic & 15.90 & 16.58 & 2.28 & 17.17 \\
Eyring(A) & 14.73 & $14.68 \pm 0.033$ & $-0.18 \pm 0.00011$ & $15.27 \pm 0.033$ \\
Eyring(B) & 14.73 & $14.73 \pm 0.033$ & $0.004 \pm 0.00011$ & $15.32 \pm 0.033$ \\
Arrhenius & 14.64 & $14.59 \pm 0.033$ & $-0.18 \pm 0.00011$ & $15.18 \pm 0.033$ \\
\hline
\end{tabular}

Table 4: Activation parameters of ylide4 for the carbon- carbon single bond in the Z-4 isomers, (I, III) by the classic method

\begin{tabular}{|c|c|c|c|c|c|c|c|}
\hline $\begin{array}{l}T_{\mathrm{c}} \\
\mathrm{K}\end{array}$ & $\begin{array}{c}\delta \\
\text { ppm }\end{array}$ & $\begin{array}{l}\Delta v \\
\mathbf{H z}\end{array}$ & $\begin{array}{l}k_{c} \\
\mathbf{S}^{-1}\end{array}$ & $\begin{array}{c}\Delta G^{\ddagger} \\
\text { kcalmol }^{-1}\end{array}$ & $\begin{array}{c}\Delta \boldsymbol{H}^{\ddagger} \\
\text { kcalmol }^{-1}\end{array}$ & $\begin{array}{c}\Delta \boldsymbol{S}^{\ddagger} \\
\text { calmol }^{-1} \mathbf{K}^{-1}\end{array}$ & $\begin{array}{c}E_{\mathrm{a}} \\
\text { kcalmol}^{-1}\end{array}$ \\
\hline 204.15 & $3.177-3.194$ & 6.80 & 15.106 & 10.69 & \multirow{3}{*}{11.70} & \multirow{3}{*}{4.97} & \multirow{3}{*}{12.11} \\
\hline & & & & & & & \\
\hline 213.15 & 5.295-5.355 & 24.013 & 53.316 & 10.55 & & & \\
\hline
\end{tabular}


of the Eyring and Arrehnius equations are also calculated $^{128-30}$. The values of activation energy and activation parameters obtained by three methods are reported in Table 3.
An evaluation of the results obtained (Table 3 ) by using three methods shows the results from the Eyring and Arrhenius are consistent, but are different from the classic method.

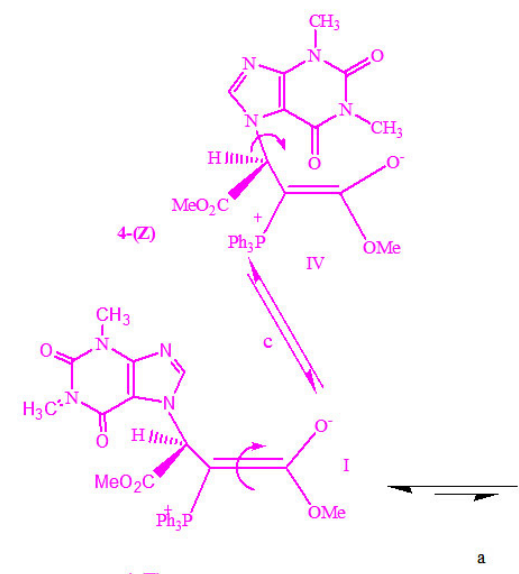

4-(Z) major rotamer

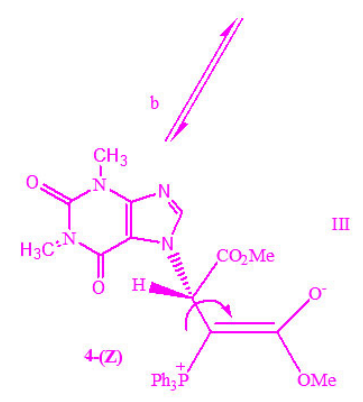

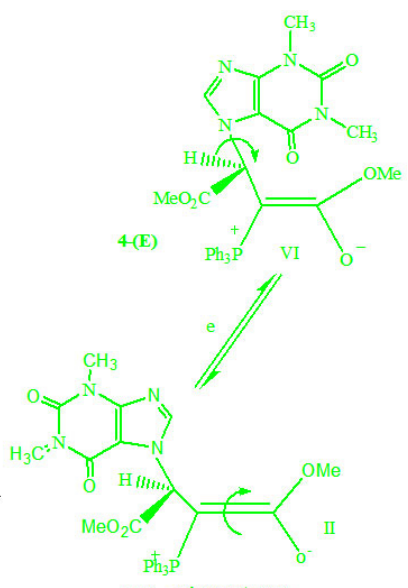

4(E) minor rotamer

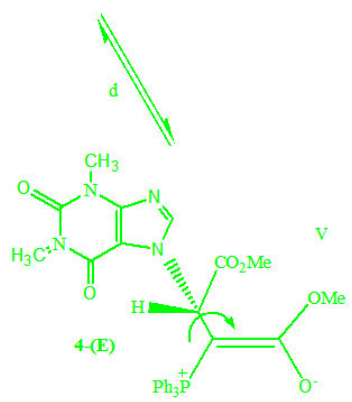

Fig. 3: The restricted rotational processes for ylide4

Table 5: Activation parameters of ylide4 for rotation around the nitrogen- carbon single bond in the Z-4 isomers, $(\mathrm{I}, \mathrm{V})$ obatiend by the classic method

\begin{tabular}{lclccccc}
\hline $\begin{array}{l}T_{c} \\
\mathbf{K}\end{array}$ & $\begin{array}{c}\delta \\
\mathbf{p p m}\end{array}$ & $\begin{array}{l}\Delta v \\
\mathbf{H z}\end{array}$ & $\begin{array}{c}\boldsymbol{K}_{\mathrm{c}} \\
\mathbf{s}^{-1}\end{array}$ & $\begin{array}{c}\Delta \boldsymbol{G}^{\ddagger} \\
\mathbf{k c a l m o l}^{-1}\end{array}$ & $\begin{array}{c}\Delta \boldsymbol{H}^{\ddagger} \\
\mathbf{k c a l m o l}^{-1}\end{array}$ & $\begin{array}{c}\Delta \boldsymbol{S}^{\ddagger} \\
\mathbf{c a l m o l}^{-1} \mathbf{K}^{-1}\end{array}$ & $\begin{array}{c}\boldsymbol{E}_{\mathrm{a}} \\
\mathbf{k c a l m o l}^{-1}\end{array}$ \\
\hline 243.15 & $8.336-8.345$ & 4 & 8.881 & 13.08 & & & 12.11 \\
247.15 & $5.447-5.462$ & 6.003 & 13.328 & 13.10 & & -5.94 & \\
\hline
\end{tabular}

Table 6: The activation parameters derived from dynamic reviewylide 4 around the carbon-carbon single bound (Entry d,Fig. 3) according to classic method

\begin{tabular}{|c|c|c|c|c|c|c|c|}
\hline $\begin{array}{l}T_{\mathrm{c}} \\
\mathrm{K}\end{array}$ & $\begin{array}{c}\delta \\
\text { ppm }\end{array}$ & $\begin{array}{l}\Delta v \\
\mathbf{H z}\end{array}$ & $\begin{array}{l}k_{c} \\
s^{-1}\end{array}$ & $\begin{array}{c}\Delta \boldsymbol{G}^{\ddagger} \\
\text { kcalmol }^{-1}\end{array}$ & $\begin{array}{c}\Delta \boldsymbol{H}^{+} \\
\text {kcalmol }^{-1}\end{array}$ & $\begin{array}{c}\Delta \boldsymbol{S}^{\ddagger} \\
\text { calmol }^{-1} \mathbf{K}^{-1}\end{array}$ & $\begin{array}{c}E_{\mathrm{a}} \\
\text { kcalmol }^{-1}\end{array}$ \\
\hline 208.15 & $3.685-3.743$ & 23.21 & 51.54 & 10.4 & & & \\
\hline 205.15 & 5.317-5.355 & 15.208 & 33.767 & 10.39 & 11.55 & 5.54 & 11.96 \\
\hline
\end{tabular}


Dynamic effect (Fig. 3, b, I and III) for the carboncarbon single bond and the nitrogen-carbon (N -C-CH) bond (Fig. 3, C, I and IV) of the Z isomer

With decreasing temperature lower than $-30 \stackrel{\circ}{ } \mathrm{C}$, a singlet from methyl proton begin to broad spectrum for the $4-Z$ isomer. The resonance coalescence can be observed at $-69{ }^{\circ} \mathrm{C}(204.15$ $\mathrm{K}$ ) and the spectrum for the $4-\mathrm{Z}$ isomer (Fig. 3, b, I and III) shows a resonance arising from (3.177-3.194ppm) in acetone- $d_{6}$ around the carboncarbon single bond. Another resonance coalescence observed at near $-60^{\circ} \mathrm{C}(213.15 \mathrm{~K})$ is belong to the methine proton $\left.\left(\mathrm{H}-\mathrm{C}-\mathrm{C}=\mathrm{P},{ }^{3} \mathrm{JPH}\right)\right)$. For this process, the activation parameters and kinetic parameters is calculated by using the classic method and is shown in Table 4.

Also, in lower temperature than $-10{ }^{\circ} \mathrm{C}$ (8.298 ppm), a singlet from proton of nitrogen in ring five-membered $(\mathrm{N}=\mathrm{CH})$ begin to broad at $-50^{\circ} \mathrm{C}$. The resonance coalescence occurs at approximately $-30^{\circ} \mathrm{C}(243.15 \mathrm{~K})$ and then the ${ }^{1} \mathrm{H}$ NMR spectrum (Fig. 3, C, I and IV) shows a resonance arising from

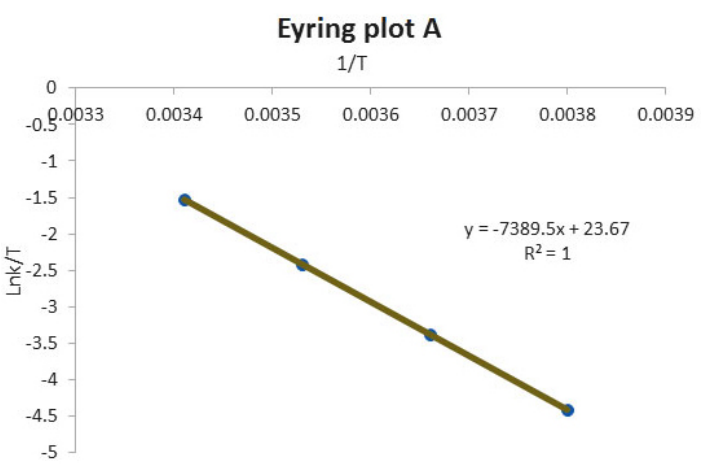

Fig. 4 A: An Eyring plot of $\ln (k / T)$ versus 1/T

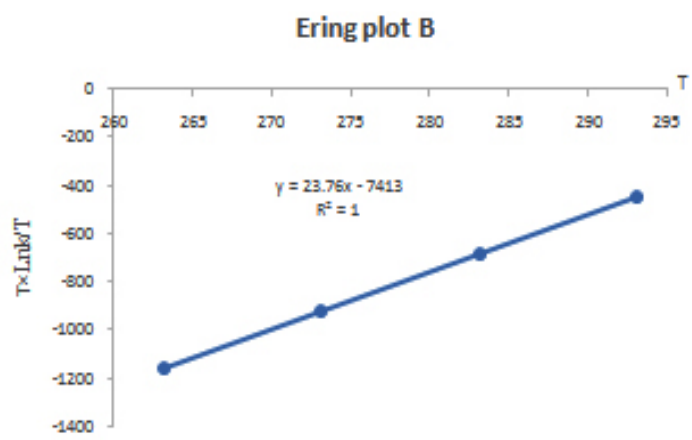

Fig. 4 B: A different linearized form of Eyring equation (8.336-8.345ppm)around the carbon-nitrogen single bond in acetone- $d_{6}$. Another resonance coalescence is accrued at near $-26{ }^{\circ} \mathrm{C}(247.15 \mathrm{~K})$ is belong to the methine proton $\left.\left(\mathrm{H}-\mathrm{C}-\mathrm{C}=\mathrm{P},{ }^{3} \mathrm{JPH}\right)\right)$ for the restricted rotational process around nitrogen-carbon single bond. The activation parameters and kinetic parameters are calculated by the classic method and is shown in Table 5.

Dynamic effect (Fig. 3, d, II and V) for the carboncarbon single bond and the 4-E rotational isomers as a result of restricted rotational processes (Fig. $3, \mathrm{e}, \mathrm{II}$ and $\mathrm{VI}$ ) around the nitrogen-carbon single bond

With decreasing temperature in lower than $-30^{\circ} \mathrm{C}$, two singlet from methoxy protons begin to broad at $-50^{\circ} \mathrm{C}$. The resonance coalescence is observed at $-65^{\circ} \mathrm{C}(20815 \mathrm{~K})$. Then the ${ }^{1} \mathrm{H}$ NMR spectrum for the 4-E isomer (Fig. 3, d, II and V) shows a resonance arising from (3.685-3.743 ppm)around the carbon-nitrogen simple bond in acetone- $d_{6}$. Another resonance coalescence is obsreved at near $-68^{\circ} \mathrm{C}(205.15 \mathrm{~K})$ is belong to the methine proton $\left.\left(\mathrm{H}-\mathrm{C}-\mathrm{C}=\mathrm{P},{ }^{3} \mathrm{JPH}\right)\right)$ for rotational process around carbon-nitrojen single bond. The activation and kinetic parameters are calculated by the classic method and are reported in Table 7.

The Eyring plot and Arrhenius plot are shown in Figs. 5 and 6 and also the activation and kinetic parameters are calculated by using the classic method and also are presented in Table 8.

The results from Eyring and Arrhenius plots are consistent together more than the classic method (Table 8). Moreover, when temperature is reduced down lower than $-10 \stackrel{\circ}{ } \mathrm{C}$ a singlet from proton of nitrogen in ring five-membered $(\mathrm{N}=\mathrm{CH})$ begin to

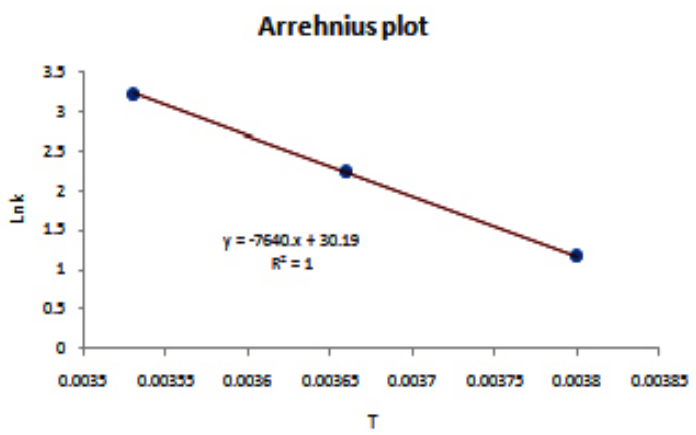

Fig. 5: An Arrhenius plot of Ink versus 1 


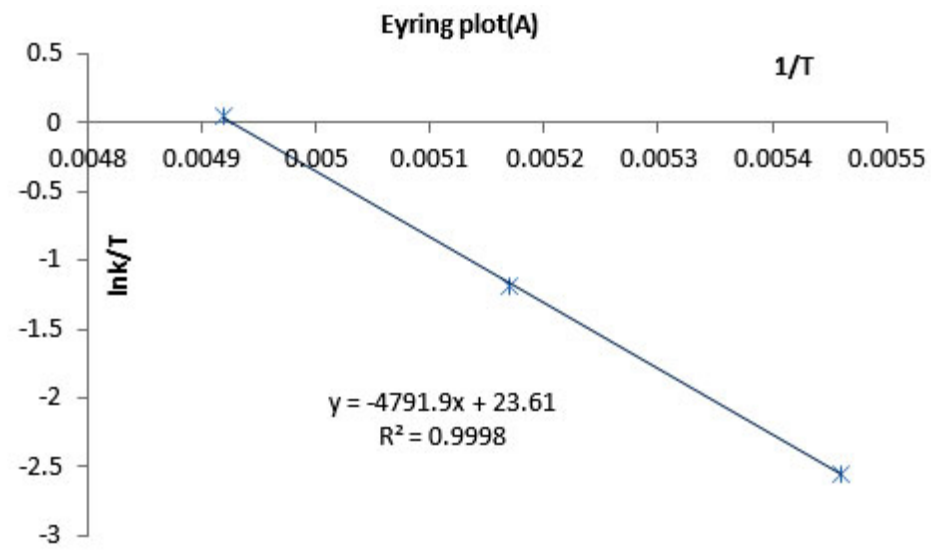

Fig. 6A: An Eyring plot of In $(k / T)$ versus 1

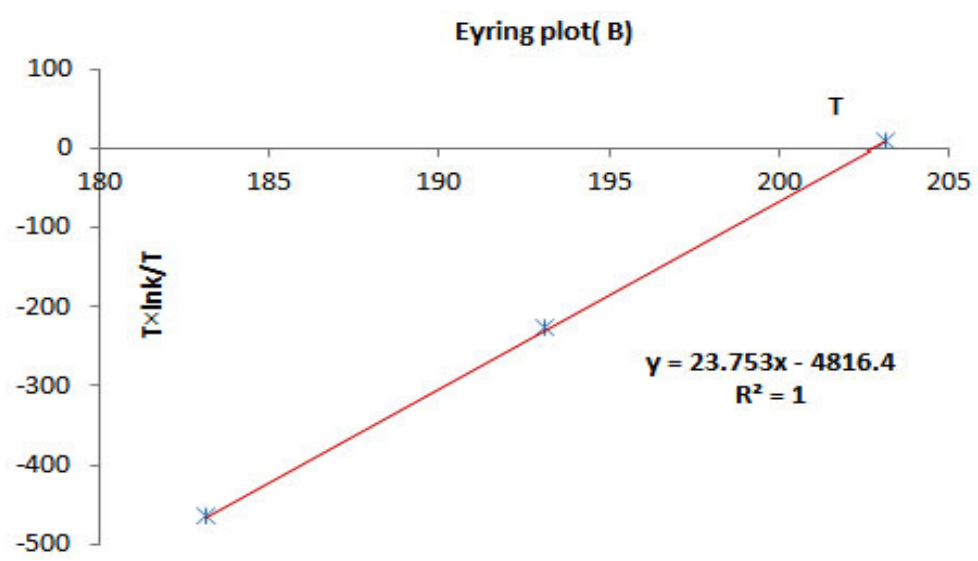

Fig. 6B: A different linearized form of Eyring equation

Table 7: Comparing the obtained results from the two methods (Eyring and Arrhenius) for the restricted rotation around the carbon-carbon single bond in the isomers $E-4$ [entry d]

\begin{tabular}{llccl}
\hline Methods & $\Delta \mathbf{G}^{\ddagger}\left(\mathbf{k c a l m o l}^{-1}\right)$ & $\Delta \mathbf{H}^{\ddagger}\left(\mathbf{k c a l m o l}{ }^{-1}\right)$ & $\Delta \mathbf{S}^{\ddagger}\left(\mathbf{k c a l m o l}^{-1} \mathbf{K}^{-1}\right)$ & $\mathbf{E}_{\mathbf{a}}\left(\mathbf{k c a l m o l}^{-1}\right)$ \\
\hline Classic & 10.40 & 11.55 & 5.54 & 11.96 \\
Eyring(A) & 9.58 & $9.52 \pm 0.1$ & $-0.30 \pm 0.00034$ & $9.93 \pm 0.1$ \\
Eyring(B) & 9.57 & $9.57 \pm 0.1$ & $-0.014 \pm 0.00034$ & $9.98 \pm 0.1$ \\
Arrhenius & 9.56 & $9.49 \pm 0.1$ & $-0.30 \pm 0.00034$ & $9.9 .91 \pm 0.1$ \\
\hline
\end{tabular}

Table 8: Activation parameters of ylide4 for rotation around the nitrogen-carbon single bond in the E-4 isomers, (II , VI) by the classic method

\begin{tabular}{lcllcccc}
\hline $\begin{array}{l}\boldsymbol{T}_{\mathbf{c}} \\
\mathbf{K}\end{array}$ & $\begin{array}{c}\delta \\
\mathbf{p p m}\end{array}$ & $\begin{array}{l}\Delta v \\
\mathbf{H z}\end{array}$ & $\begin{array}{c}\boldsymbol{k}_{\mathrm{c}} \\
\mathbf{s}^{-1}\end{array}$ & $\begin{array}{c}\Delta \boldsymbol{G}^{\ddagger} \\
\mathbf{k c a l m o l}^{-1}\end{array}$ & $\begin{array}{c}\Delta \boldsymbol{H}^{\#} \\
\mathbf{k c a l m o l}^{-1}\end{array}$ & $\begin{array}{c}\Delta \boldsymbol{S}^{\ddagger} \\
\text { calmol }^{-1} \mathbf{K}^{-1}\end{array}$ & $\begin{array}{c}\boldsymbol{E}_{\mathrm{a}} \\
\mathbf{k c a l m o l}^{-1}\end{array}$ \\
\hline 244.15 & $8.393-8.404$ & 4.40 & 9.77 & 13.09 & & & \\
& & & & & 9.49 & -14.7 & 9.94 \\
246.15 & $5.408-5.421$ & & & & 5.202 & 11.55 & 13.2 \\
\hline
\end{tabular}




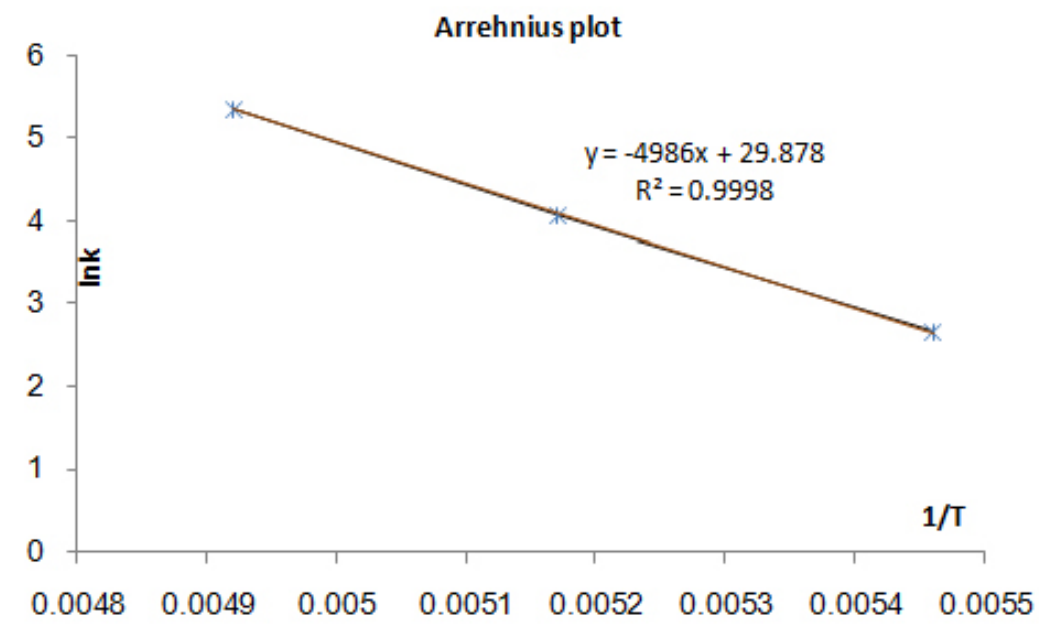

Fig. 7: An Arrhenius plot of In (k) versus 1/T

broad at $-25^{\circ} \mathrm{C}$. The resonance coalescence occurs at $-29{ }^{\circ} \mathrm{C}(244.15 \mathrm{~K})$. Then the ${ }^{1} \mathrm{H}$ NMR spectrum for the 4-E isomer (Fig. 3, e, II and VI) shows a resonance arising from (8.393-8.404ppm)around the carbon-nitrogen simple bond in acetone- $d_{6}$. Another resonance coalescence is accrued at near $-27^{\circ} \mathrm{C}(246.15 \mathrm{~K})$ in relation to the methene proton $\left.\left(\mathrm{H}-\mathrm{C}-\mathrm{C}=\mathrm{P},{ }^{3} \mathrm{JPH}\right)\right)$ which is relevant to restricted rotational process around carbon-nitrogen single bond. For this process, the activation parameters and kinetic parameters obtained using the classic method is tabulated in Table 9. Because of lone pair inversion of nitrogen atom in hetero atom fivemembered ring, rotation around the carbon-carbon single bond requires a barrier rotational energy more than the carbon-carbon single bond (comparison between $E_{\mathrm{a}}$ and $\Delta G^{\ddagger}$ in Table 9 ).

\section{CONCLUSION}

The three most common methods for calculating the activation parameters of the restricted rotational isomers are used. Results obtained from the Eyring and Arrhenius methods were consistent, however, were different with the classic method for the carbon-carbon double bond. Results from Eyring and Arrhenius plots agree more than the classic method for carbon-carbon single bond in $E$ isomer. The activation parameters were calculated using the classic method (single point) for nitrogen-carbon in $E$ and $Z$ isomer and carbon-carbon $Z$ isomer. The
Eyring and Arrhenius method did not use in these rotation because required data were not available. Because of the strong conjugation with the adjacent carbonyl group, the value of activation barrier energy $\left(\Delta G^{\ddagger}\right)$ of the restricted rotation around the partial carbon-carbon double bond $\left(\mathrm{MeO}_{2} \mathrm{C}=\mathrm{CPPh}_{3}\right)$ was larger than the nitrogen-carbon $(\mathrm{N}-\mathrm{C}-\mathrm{CH})$ and carbon-carbon $\left(\mathrm{MeO}_{2} \mathrm{CH}-\mathrm{C}-\mathrm{C}=\mathrm{PPh}_{3}\right)$ single bonds. As a case study, because of the lone pair inversion of nitrogen atom in hetero atom -membered ring, rotation around the carbon-nitrogen single bond needs a barrier rotational energy more than the carbon-carbon single bond. Rotation around the carbon-carbon double bond $\Delta G^{\ddagger}$ has a more positive value. So high value of $\Delta G^{\ddagger}$ indicates the rate of this process is slow at room temperature. At higher temperature it is fast and spontaneous. Rotation around the carbon-carbon single bond $\Delta G^{\ddagger}$ has low value (less position value), so rotation around the carbon-carbon single bond is a fast process and spontaneous at room temperature, observation of two conformers (I, II or III and IV) on the basis of this rotation at low temperature is a good evidence for the process that is not spontaneous under this condition.

\section{ACKNOWLEDGEMENT}

We gratefully acknowledge financial support from the Research Council of the University of Sistan and Baluchestan. 


\section{REFERENCES}

1. Tawkir, M.; Iqbal, S. A.; Krishan, B.; Zaafarany, I. Orient. J. Chem. 2011, 27(2), 603-609.

2. Hazeri, N.; Habibi-Khorassani, S. M.; Maghsoodlou, M. T.; Marandi, G.; Nassiri, M.; Shahzadeh, G. J. Chem. Res.2006, 3, 215-217.

3. Maghsoodlou, M. T.; Habibi-Khorassani, S. M.; Hazeri, N.; Nassiri, M.; Kakaei, R.; Marandi, G. Phosphorus, Sulfur Silicon Relat. Elem.2006, 181(3), 553-560.

4. Maryanoff, B. E.; Rietz, A. B. Chem. Rev. 1989, 89(4), 863-927.

5. An-Hu, L.; Li-Xin, D.; Aggrwal, V. Chem. Rev. 1997, 97(6), 2341-2372.

6. Kolodiazhnyi, O. I. Russ. Chem. Rev.1997, 66(3), 225-254.

7. Pietrusiewiz, K. M.; Zablocka, M. Chem. Rev. 1994, 94(5), 1375-1411.

8. Profire, L.; ${ }^{a}$ unel, V.; Lupascui, D.; Baican, M. C.; Bibire, N.; Vasile, C. Farmacia. 2010, 58(2),170-176.

9. Barnes, P. J.; Pauwels, R. A. Eur. Respir. J. 1994, 3, 579-591.

10. Kawayama, T.; Hoshino, T.; Ichiki, M.; Tsuda, T.; Kinoshita, M.; Takata, S.; Koga, T.; Iwanaga, T.; Aizawa, H. Int. J. Chron. Obstruct. Pulmon. Dis.2008, 3(1), 137-148.

11. Korzycka, L.; Górska, D. J. Pharm. Pharmacol. 2008, 60(5), 637-645.

12. Majumdar, S.; Sloan, K. B. Int. J. Pharm. 2007, 33, 64-71.

13. Marwick, J. A.; Ito, K.; Adcoc, I. M.; Kirkham, P.A. Expert Opin. Ther.Targets.2007, 11(6), 745-755.

14. Buck, M. L.; D. Marcia.; Pharm. 2008, 14, 6-20.

15. Finney, M. JB.; Karlson, J. A.; Persson, C. J. Pharmacol. 1985, 85, 29-36.

16. Guillot, C.; Fornaris, M.; Badger, M.; Orehek, J. J. Allergy. Clinlmmunol. 1984, 74(5), 713718.

17. Finnerty, J. P.; Lee, C.; Wilson, S.; Madden,
J.; Djukanovic, R.; Holgate, S.T.; Eur. Respir. J.1996, 9, 1672-1677.

18. Auchampach, J. A.; Kreckler, L. M.; Wan, T. C.; Maas, J. E.; Hoeven, D. V.; Gizewski, E. Narayanan, J.; Maas, G. E. J. Pharmacol. Exp. Ther.2009, 329(1), 2-13.

19. Srdjenovic, B.; Djordjevic-Milicn, V.; Grujic, R.; Injac, Z. J. Chromatogra. Sci.2008, 46(2), 144-149.

20. Anet, F. A. L.; Anet, R.; Cotton, F. A.; Jackman, L.M. Eds., Academic Press: New York, 1979.

21. Mofarrah, E.; Habibi-Khorassani, S. M.; Maghsoodlou, M.T.; Shahraki, M. Indian J. Chem. Sect B. 2015, 54(B), 1528-1534.

22. Mofarrah, E.; Habibi-Khorassani, S. M.; Maghsoodlou, M. T.; Shahraki M. Appl. Magn. Reson. 2015, 46 (10), 1179-1188.

23. Habibi-Khorassani, S.M.; Maghsoodlou, M.T.; Ebrahimi, A.; Mohammadi, M.; Shahraki, M.; Aghdaei, E. J. Phys. Org. Chem.2012, 25(12), 1328-1335.

24. Habibi-Khorassani, S. M.; Shahraki, M.; Maghsoodlou, M.T.; Erfani, S. Spectrochim. Acta, Part A. 2015, 145, 410-416.

25. Habibi-Khorassani, S. M.; Shahraki, M.; Maghsoodlou, M. T.; Mofarrah, El.; Mofarrah, EL.; Mousavi, S. R. Biomed. Pharmacol. J. 2015, 8(2), 565-572.

26. Aghdaei, E.; Habibi-Khorassani, S. M.; Shahraki, M. Orient. J. Chem. 2015, 31(4), 2427-2433.

27. Zimmer, K. D.; Shoemaker, R.; Rumi-Ski R. R. Inorganic Chemical Acta. 2006, 359(5), 1478-1484.

28. Lente, G.; Fabian, I.; Poe, A. J.; New J. Chem. 2005, 29(6), 759-760.

29. Espenson, J. H. McGraw-Hill, New York, 1995, 2,158 .

30. Poe, A. J.; ed. Twigg, M.V. Plenum Press. 1994, 8,10, 220. 